\title{
Probing the Electronic Structure of Spectator Oxo Ligands by ${ }^{17} \mathrm{O}$ NMR Spectroscopy
}

\author{
Christopher P. Gordon§ and Christophe Copéret* \\ §SCS-Metrohm Award for the Best Oral Presentation in Catalysis Science \& Engineering
}

\begin{abstract}
Spectator oxo ligands are ubiquitous in catalysis, in particular in olefin epoxidation and olefin metathesis. Here we use computationally derived ${ }^{17} \mathrm{O}$ NMR parameters to probe the electronic structure of spectator oxo ligands in these two reactions. We show that ${ }^{17} \mathrm{O}$ NMR parameters allow to distinguish between doubly-bonded and triply-bonded oxo ligands, giving detailed insights into the frontier molecular orbitals involved in the metaloxo bonds along the reaction pathway. On the one hand, our study shows that in olefin epoxidation catalysed by methyltrioxorhenium (MTO), the oxo ligand significantly changes its bonding mode upon formation of the oxygen-transferring Re-oxo-bisperoxo-species, changing its nature from a doubly bonded to a triply bonded oxo ligand. On the other hand, only minor changes in the binding mode are found along the olefin metathesis reaction pathway with Mo- and W-based oxo-alkylidene species, in which the oxo ligand behaves as a triply bonded ligand throughout the reaction. This finding contrasts earlier studies that proposed that the change of binding mode of the oxo ligand was key to metallacyclobutane formation.
\end{abstract}

Keywords: Chemical shift tensor · NMR spectroscopy · Olefin epoxidation · Olefin metathesis · Spectator oxo ligand

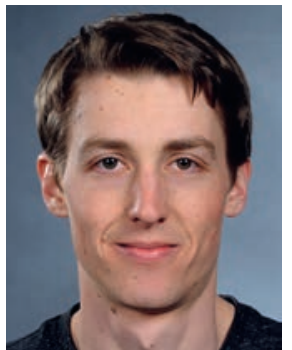

Christopher P. Gordon was awarded a Bachelor's degree in Chemistry at ETH Zurich in 2015. He completed his Master's degree at ETH Zurich under the Excellence Scholarship and Opportunity Programme in 2017 and was awarded the ETH Medal for his Master's thesis. He is currently pursuing a $\mathrm{PhD}$ degree in the group of Prof. Christophe Copéret at ETH Zurich, focusing on chemical shift as a descriptor to understand reactive intermediates in catalysis.

\section{Introduction}

Metal oxo complexes are ubiquitous in catalysis and play a particularly important role in both olefin epoxidation and olefin metathesis. ${ }^{[1]}$ Catalysts engaging in these reactions often feature an oxo ligand that is not directly involved in the reaction and merely acts as a spectator. In 1980, Rappé and Goddard pointed out that this spectator oxo ligand is, however, crucial in modulating the electronic structure of catalysts along the reaction pathway. In their seminal paper ${ }^{[2]}$ and two more detailed follow-up studies, ${ }^{[3,4]}$ Rappé and Goddard discussed that the coordination mode between the metal and the spectator oxo ligand varies between two extreme structures, described as a metal-oxo double bond and a metal-oxo triple bond, respectively. In metal bisoxo (or tris-oxo) and oxo-alkylidene complexes, two (or more) $\pi$-bonding ligands compete for the same metal d-orbitals. Hence, the spectator oxo ligand in these complexes is best described as a doubly bonded ligand. However, in the corresponding metallacyclobutane, formed upon reaction with an olefin, the spectator oxo ligand could in principle engage in two $\pi$-bonding interactions and is hence best described as a triply bonded metal-oxo (Fig. 1a). Rappé and Goddard suggested that the changing bonding mode of the spectator oxo ligand drives the metallacycle formation, as the metal-oxo interaction gets stronger upon reaction with the olefin.

It should be noted that in 1980, when Rappé and Goddard developed the model of the spectator oxo ligand, the reaction mechanisms of neither olefin metathesis nor olefin epoxidation were known in detail. While the Chauvin-mechanism of olefin metathesis was already proposed in $1971,{ }^{[5]}$ the exact geometry of the metallacyclobutane intermediate and its importance for the olefin metathesis reaction were not completely elucidated. Only later has it been shown that olefin metathesis occurs via the formation of a metallacyclobutane of trigonal-bipyramidal (TBP) structure, while square-planar (SP) metallacyclobutanes are off-cycle intermediates (Fig. 1b). ${ }^{[6-9]}$ Similarly, the mechanism of metal-catalysed olefin epoxidations with $\mathrm{d}^{0}$ metals was subject to debate; both insertion-type and outer sphere mechanisms were proposed for the olefin epoxidation and olefin dihydroxylation reaction. ${ }^{[10]}$ Today, outer-sphere mechanisms are generally accepted to predominate (Fig. 1b). ${ }^{[11]}$

The currently accepted mechanistic models for olefin metathesis and olefin epoxidation are hence significantly different to those studied by Rappé and Goddard in their seminal work. This entails the question whether the spectator oxo ligand actually plays the role that was put forward in the 1980s. In this work, we will hence study the electronic structure of the spectator ligands in the olefin epoxidation reaction catalysed by methyltrioxorhenium (MTO) ${ }^{[12-14]}$ as well as in the olefin metathesis reaction catalysed by Mo and $\mathrm{W}$ oxo-alkylidene species, that are proposed key inter- 
a) Rappé \& Goddard (1980): Spectator oxo effect i) olefin metathesis<smiles>C#CC=[W](=O)Cl</smiles><smiles>O=[W]1(Cl)CCC1</smiles>

ii) olefin epoxidation

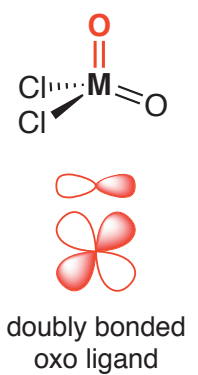

b) Mechanisms accepted today i) olefin metathesis

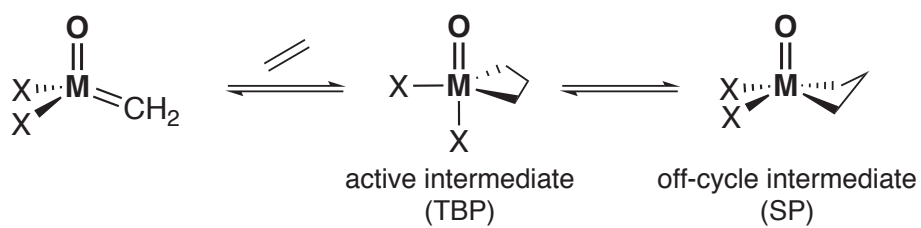

ii) outer-sphere epoxidation (example: methyltrioxorhenium)

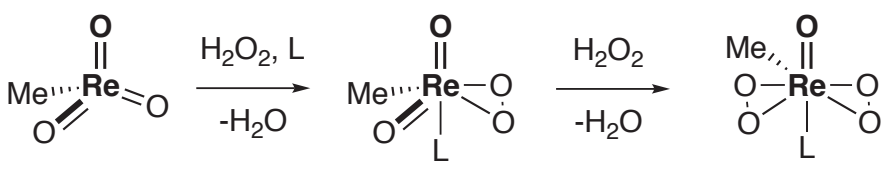
$\mathrm{L}=$ pyridine (or derivatives)

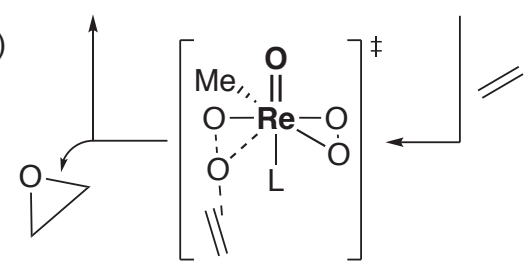

Fig. 1. a) Spectator oxo effect as proposed by Rappé and Goddard. b) Currently accepted mechanisms of i) olefin metathesis and ii) olefin epoxidation with $\mathrm{d}^{0}$ metals.

mediates for the industrial metathesis catalysts based on supported group 6 metal oxides. ${ }^{[15,16]}$

The study of the electronic structure of these metal complexes will be based on ${ }^{17} \mathrm{O}$ NMR parameters (chemical shift and quadrupolar coupling) because their analysis has recently emerged as a powerful tool to understand the electronic structure of NMR active nuclei. ${ }^{[17-20]}$ In fact, we have recently shown that the ${ }^{17} \mathrm{O}$ NMR parameters of peroxo species can be of predictive value for the propensity of these species to engage in olefin epoxidation. ${ }^{[21]}$ In particular, peroxo species active in epoxidation feature highly deshielded ${ }^{17} \mathrm{O}$ chemical shifts as well as larger quadrupolar coupling constants $\left(C_{Q}\right)$ as compared to peroxo species that do not engage in epoxidation. This correlation between NMR parameters and reactivity is due to a specific electronic structure that enables olefin epoxidation, namely two co-planar lone-pairs on the two peroxo oxygen atoms, that weaken the $\mathrm{O}-\mathrm{O}$ bond while raising the energy of the lone-pairs, thus generating an ideal electronic structure for epoxidation reactivity.

In this work, we will interrogate the change of electronic structure of the spectator oxo ligand during the formation of peroxo compounds and metallacyclobutane intermediates in olefin epoxidation and olefin metathesis, respectively, by analysing the corresponding ${ }^{17} \mathrm{O}$ NMR parameters in detail. We will focus on two model reactions, i.e. the olefin epoxidation with MTO in the presence of $\mathrm{H}_{2} \mathrm{O}_{2}$, and the [2+2] cycloaddition of an olefin to a group 6 oxo-alkylidene species. We will show that NMR spectroscopy is a suitable tool to distinguish metal-oxygen double bonds from metal-oxygen triple bonds, thus directly capturing the essence of the spectator oxo effect. Our analysis suggests that the oxo ligand significantly changes its coordination mode upon formation of peroxo intermediates in olefin epoxidation, generating a triply bonded oxo ligand. The changes are much less pronounced upon metallacyclobutane formation in olefin metathesis, in which the oxo ligand behaves like a triply bonded ligand throughout the reaction.

\section{Methodology}

The chemical shielding tensors and electric field gradient (EFG) tensors shown in this contribution were obtained by first optimizing the molecular structures with the gaussian09 program ${ }^{[22]}$ (using a PBE0 functional[23] in combination with pcseg-2 basis sets of triple- $\zeta$ quality ${ }^{[24]}$ and quasi-relativistic effective core potentials of the Stuttgart-group and the associated basis sets on metal atoms ${ }^{[25,26]}$ ). NMR calculations were performed using ADF 2014 within the GIAO framework, ${ }^{[27]}$ with a PBE0 functional[23] and Slater-type basis sets of triple- $\zeta$ quality. For the NMR calculations, relativistic effects were treated by the 2-component zeroth order regular approximation (ZORA).[28,29] The obtained NMR shielding tensors are analysed using scalar relativistic natural localized molecular orbitals (NLMOs), obtained with the NBO 6.0 program. ${ }^{[30]}$

\subsection{Chemical Shift Tensors and Quadrupolar Coupling Constants}

The chemical shift tensor is a second-rank tensor with three principal components defined as $\delta_{11} \geq \delta_{22} \geq \delta_{33}$ (Fig. 2a). The average of these three components corresponds to the isotropic chemical shift $\delta_{\text {iso }}$. Chemical shift for a measured nucleus thus depends on the orientation of the molecule with respect to the magnetic field. In solution, only the isotropic chemical shift $\delta_{\text {iso }}$ is measured, because molecular tumbling removes the orientation dependence. In solid-state NMR of amorphous or microcrystalline samples, so-called powder patterns are observed, in which the three principal components of the chemical shift tensor can be measured and their superpositions are represented according to the statistical orientation of molecules. The three components of the chemical shift tensor are orthogonal to each other and their magnitude and orientation can provide significant insight into the local electronic structure of molecules. [17,31]

The chemical shift values $(\delta)$ are reported with respect to a reference compound, whose chemical shift is arbitrarily set to 0 ppm. For ${ }^{17} \mathrm{O}$ NMR spectra, water $\left(\mathrm{H}_{2} \mathrm{O}\right)$ is typically used as a reference and set to $0 \mathrm{ppm}$. Chemical shielding $(\sigma)$ on the other hand is an intrinsic property of the nuclei in molecules which describes the shielding or deshielding of a nucleus with respect to the bare nucleus (e.g. the $\mathrm{O}^{8+}$ nucleus) whose shielding is set to $0 \mathrm{ppm}$. Chemical shielding $(\sigma)$ and chemical shift $(\delta)$ are hence linearly related and only differ in their origin $\left(\delta_{\text {ii }}=\sigma_{\text {iso,ref }}-\sigma_{\text {ii }}\right)$. While experimentally, only the chemical shift $(\delta)$ can be measured, in computational approaches (e.g. DFT calculations) the chemical shielding $(\sigma)$ is calculated (Fig. 2a).

DFT calculations also enable further analyses of the chemical shielding, which allow to understand the relation between chemical shielding (or chemical shift) and the molecular electronic 
structure. For instance, each principal component of the chemical shielding tensor $\left(\sigma_{\mathrm{ij}}\right)$ can be decomposed into diamagnetic $\left(\sigma_{\text {dia }}\right)$ and paramagnetic $\left(\sigma_{\text {para }}\right)$ terms (Eqn. (1)). The diamagnetic shielding arises from so-called diamagnetic currents which are induced by the magnetic field in the core orbitals and causes a rather isotropic shielding of the nucleus. In most cases, core orbitals are similar among nuclei in various chemical environments and hence the diamagnetic shielding is usually rather independent of the local molecular structure (e.g. the oxygen 1s orbital in $\mathrm{H}_{2} \mathrm{O}$ is not significantly different from that in $\mathrm{H}_{2} \mathrm{O}_{2}$ ). On the other hand, the paramagnetic shielding arises from paramagnetic currents that are induced in the frontier orbitals of a molecule (energetically high-lying occupied and low-lying unoccupied orbitals). The paramagnetic shielding can hence be described as the shielding arising from the interaction of the molecular electronic ground state with excited states by a coupling through the angular momentum operator $\hat{L}$ (Eqn. (2) and Fig. 2b). ${ }^{[32]}$ Typically, such orbital interactions lead to deshielding; this deshielding is particularly pronounced for the coupling of energetically low-lying excited states and a high-lying ground state, corresponding to frontier molecular orbitals of appropriate symmetry to allow magnetically induced coupling. In a more intuitive view, a large paramagnetic deshielding of a nucleus is expected along a direction $i$, whenever a high-lying occupied orbital on this nucleus can be superimposed on a low-lying vacant orbital on the same nucleus by a rotation by $90^{\circ}$ along the $i$-axis (Fig. 2b). ${ }^{[17]}$

$$
\sigma_{i i}=\sigma_{i i, \mathrm{dia}}+\sigma_{i i \mathrm{para}+\mathrm{SO}}
$$

$$
\sigma_{i i, \text { para }} \Leftrightarrow-\frac{\left\langle\Psi_{\mathrm{occ}}\left|\hat{L}_{i}\right| \Psi_{\mathrm{vac}}\right\rangle\left\langle\Psi_{\mathrm{vac}}\left|\hat{L}_{i} / r^{3}\right| \Psi_{\mathrm{occ}}\right\rangle}{\Delta E_{\mathrm{vac}-\mathrm{occ}}}
$$

In addition to determining the diamagnetic and paramagnetic contributions to the chemical shielding tensor, DFT calculations also allow for the identification of the effect of specific frontier orbitals on the paramagnetic shielding. For instance, the so-called Natural Chemical Shielding (NCS) analysis allows to understand the shielding tensor based on contributions of individual Natural Localized Molecular Orbitals (NLMOs). ${ }^{[33,34]}$ Since NLMOs correspond to bonds and lone pairs this analysis of the chemical

a) Chemical shift tensor $\delta$ and relation to shielding $\sigma$

$$
\left(\begin{array}{ccc}
\delta_{11} & 0 & 0 \\
0 & \delta_{22} & 0 \\
0 & 0 & \delta_{33}
\end{array}\right) \quad \begin{aligned}
& \delta_{11} \geq \delta_{22} \geq \delta_{33} \\
& \delta_{\mathrm{ii}} \approx \sigma_{\text {iso,ref }}-\sigma_{\mathrm{ii}}
\end{aligned}
$$

b) Paramagnetic deshielding and electronic structure

$\frac{\sigma_{\text {ii,para }} \Leftrightarrow \frac{\left\langle\Psi_{\text {occupied }}\left|\widehat{L}_{i} / r^{3}\right| \Psi_{\text {vacant }}\right\rangle}{\Delta E_{\text {vacant-occupied }}}}{\sigma_{\text {yy,para }} \text { is large if } \Delta \mathrm{E}_{\text {vacant-occupied }} \text { is small and if }}$

Fig. 2. a) The chemical shift tensor $\delta$ and its relation to the chemical shielding tensor $\sigma$. b) Orbital origin of the paramagnetic contributions to the shielding tensor, which usually leads to deshielding. shielding allows for a very intuitive view of the origin of a specific chemical shielding.

As ${ }^{17} \mathrm{O}$ is a quadrupolar nucleus $(\mathrm{I}=5 / 2)$, in addition to the information contained in the chemical shift, the quadrupolar coupling holds information about the distribution of charges around the nucleus. The quadrupolar coupling is proportional to the electric field gradient (EFG) tensor. ${ }^{[35]}$ While we will not analyse EFG tensors in detail in this work, this property contains information about the charge distribution around a nucleus and has been a valuable tool to assess local symmetry around quadrupolar nuclei (e.g. $\left.{ }^{17} \mathrm{O},{ }^{27} \mathrm{Al},{ }^{45} \mathrm{Sc}\right) \cdot{ }^{[36-39]}$

\section{The Spectator Oxo Ligand During Olefin \\ Epoxidation}

MTO is a prototypical epoxidation catalyst, able to efficiently epoxidise olefins in the presence of hydrogen peroxide $\left(\mathrm{H}_{2} \mathrm{O}_{2}\right)^{[10,12]}$ Upon reaction with $\mathrm{H}_{2} \mathrm{O}_{2}$, MTO can form mono- and bisperoxo species. The oxygen-transferring key intermediate has been proposed to be the rhenium-oxo-bisperoxo species (Fig. 1b). ${ }^{40]}$ Commonly, the reaction is carried out in the presence of pyridine or pyridine derivatives; the pyridine stabilizes the peroxo species and protects the epoxide from ring opening by subsequent Lewis acid-catalysed reaction, while additionally acting as a phase-transfer catalyst. ${ }^{[13,14,41]}$ In the following, we will discuss the spectator oxo ligand and the development of the $\mathrm{Re}=\mathrm{O}$ bond throughout the formation of the oxygen-transferring species (Fig. 1b)

In MTO, the $\mathrm{Re}=\mathrm{O}$ bond length is calculated to be $1.692 \AA$. In the corresponding mono-peroxo and bis-peroxo species (both stabilized by pyridine), the $\mathrm{Re}=\mathrm{O}$ bond length decreases to 1.680 $\AA$ and $1.666 \AA$, respectively. The shortening of this bond indicates a stronger $\mathrm{Re}=\mathrm{O}$ interaction upon formation of peroxo intermediates. To probe the electronic structure of the $\mathrm{Re}=\mathrm{O}$ bond, we calculated the ${ }^{17} \mathrm{O}$ NMR parameters of the spectator oxo ligand throughout the reaction. Upon going from MTO to the corresponding mono- and bisperoxo species, the calculated isotropic ${ }^{17} \mathrm{O}$ chemical shift of the oxo ligand changes from $894 \mathrm{ppm}$ to $857 \mathrm{ppm}$ and $797 \mathrm{ppm}$, respectively. The increased shielding of the oxo ligand upon peroxo-formation is in agreement with the experimentally measured ${ }^{17} \mathrm{O}$ chemical shift, which decreases from $829 \mathrm{ppm}$ in MTO to $762 \mathrm{ppm}$ in the bisperoxo compound. ${ }^{[42]}$ The simulated calculated spectral signatures as well as the calculated chemical shift tensors and quadrupolar coupling parameters are shown in Fig. 3. The simulated spectra show a remarkable change in electronic structure of the $\mathrm{Re}=\mathrm{O}$ bond upon going from MTO and the monoperoxo- to the bisperoxo-species. While the former show one very deshielded component of the chemical shift tensor $\left(\delta_{11}\right)$, the bisperoxo-species shows an almost axially symmetric chemical shift tensor with two highly deshielded components $\left(\delta_{11}\right.$ and $\delta_{22}$ ), while $\delta_{33}$ is highly shielded. Hence, while the oxo ligand in MTO and the corresponding monoperoxo-species is highly deshielded in only one direction, it is highly deshielded in two directions in the case of the bisperoxo-species.

As discussed in the introduction, the nuclear shielding is a property that depends on the relative energy and symmetry of frontier molecular orbitals. The ${ }^{17} \mathrm{O}$ NMR parameters shown in Fig. 3 hence contain valuable information on the electronic structure of the spectator oxo ligand. We thus performed an orbital analysis of the chemical shielding tensors of the oxo ligands; this analysis allows to pin-point which frontier orbitals are responsible for the observed deshielding.

Fig. 3 (right side) shows the orbital contributions of the most relevant NLMOs of the oxo ligand to the shielding of the ${ }^{17} \mathrm{O}$ nucleus in the form of histograms. Note that the components of the shielding tensor $\sigma_{\mathrm{ij}}$ (blue bar) correspond to the sum of the diamagnetic contributions (black bar) and paramagnetic contributions (red bar). While the diamagnetic contributions are basically constant for all $\sigma_{\mathrm{ii}}$ in all studied compounds, the paramagnetic 


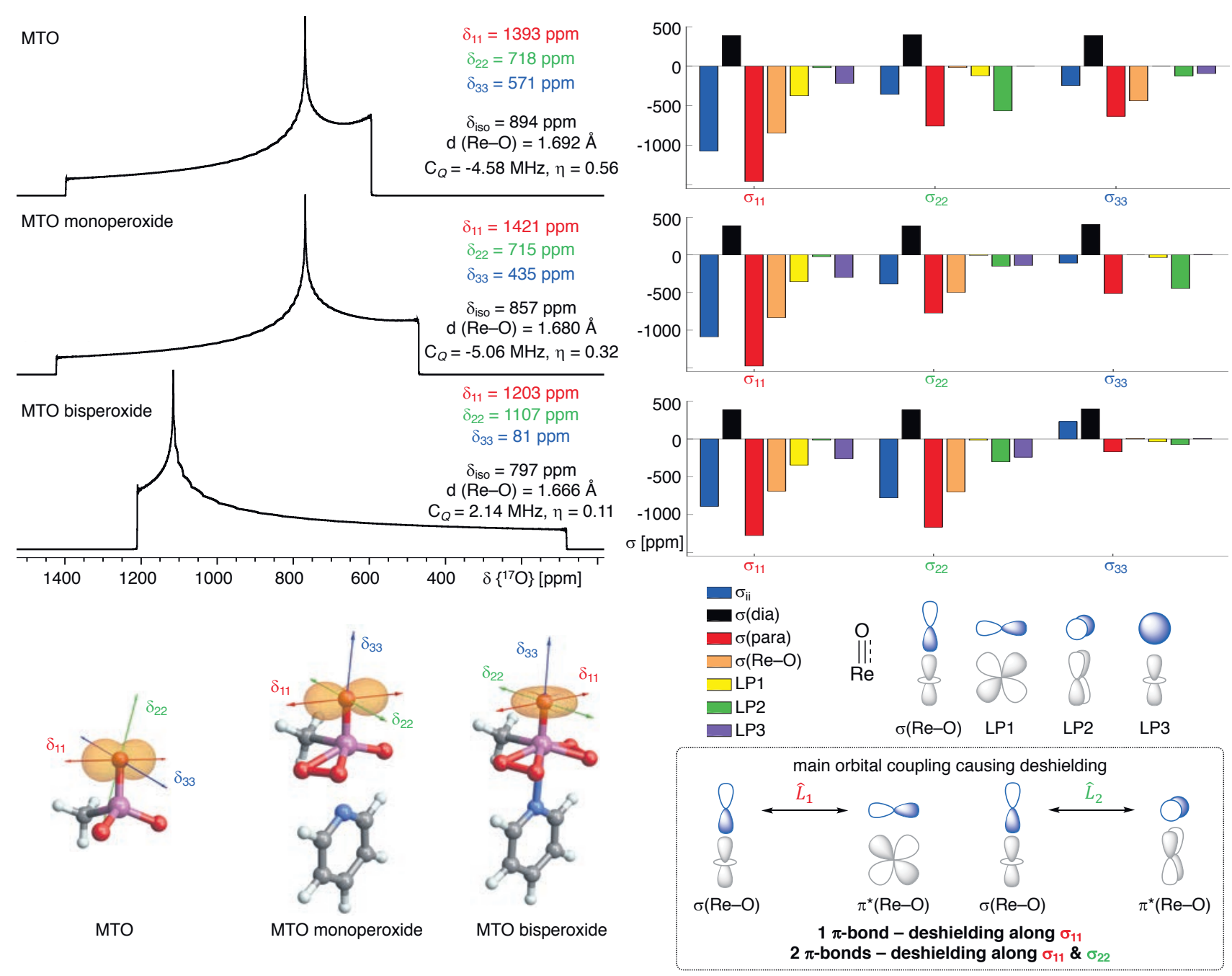

Fig. 3. Simulated NMR signatures and orbital contributions of the oxo ligand in MTO, MTO monoperoxide and MTO bisperoxide.

contributions are responsible for the variations among the $\sigma_{\mathrm{ii}}$. For MTO and the corresponding monoperoxide the $\sigma_{11}$ component is highly deshielded, while $\sigma_{22}$ and $\sigma_{33}$ are more shielded. The main orbital contribution to deshielding of $\sigma_{11}$ in these compounds arises from the bonding $\sigma(\mathrm{Re}-\mathrm{O})$ orbital, which is a high-lying occupied orbital. This orbital gives rise to deshielding by a magnetic coupling to the low-lying $\pi *(\operatorname{Re}-\mathrm{O})$ orbital, which corresponds to the antibonding combination of a metal d-orbital with the lone-pair on oxygen, arising from the $\pi$-bonding interaction between the metal and the oxo ligand. In other words, the $\pi$-bond between the metal and the oxo ligand generates an energetically low-lying vacant orbital with contribution on oxygen (the $\pi^{*}(\mathrm{M}-\mathrm{O})$ orbital), which is responsible for the large observed deshielding. This deshielding is hence indicative of the presence of a $\pi$-bonding interaction. In the bisperoxo species derived from MTO, not only the $\sigma_{11}$, but also the $\sigma_{22}$ component is highly deshielded. In fact, the shielding tensor (Fig. 3, bottom) is almost axially symmetric with respect to the $\mathrm{Re}-\mathrm{O}$ axis, indicating that the two directions perpendicular to this bond show a very similar electronic structure. The orbital analysis of both $\sigma_{11}$ and $\sigma_{22}$ show that the large deshielding of these components originates mainly from the $\sigma(\mathrm{Re}-\mathrm{O})$ orbital. The deshielding of both directions perpendicular to the $\mathrm{Re}-\mathrm{O}$ axis originating from the $\sigma(\operatorname{Re}-\mathrm{O})$ orbital indicates the presence of two low-lying $\pi^{*}(\mathrm{Re}-\mathrm{O})$ orbitals and is hence indicative of two $\pi$-bonding interactions between the metal and the oxo ligand, and hence of a triply-bonded oxo ligand.

Analysis of the ${ }^{17} \mathrm{O}$ NMR chemical shift tensors of the spectator oxo ligand in MTO and its associated peroxo-species hence shows that upon formation of a bisperoxo species the spectator oxo ligand changes its electronic structure and develops from a doubly bonded ligand to a triply bonded ligand. Notably, this information is derived from all three components of the chemical shift tensor, and would be difficult to obtain purely based on the isotropic chemical shift. The analysis of the NMR chemical shift tensor of the spectator oxo ligand indeed reveals the electronic structure that has been proposed by Rappé and Goddard, i.e. that this ligand forms a $\mathrm{Re}-\mathrm{O}$ triple bond, thus driving the formation of peroxo intermediates.

\section{The Spectator Oxo Ligand During Olefin Metathesis}

The importance of the spectator oxo ligand has not only been discussed in the framework of olefin epoxidation, but also in olefin metathesis. Rappé and Goddard suggested that the formation of metallacyclobutanes from metal alkylidenes in olefin metathesis is assisted by the spectator oxo ligand. The spectator oxo ligand was suggested to develop from a doubly bonded ligand to a triply bonded ligand upon [2+2] cycloaddition. We hence performed a similar analysis as shown above for MTO for prototypical olefin metathesis catalysts, bearing $\mathrm{Mo}=\mathrm{O}$ and $\mathrm{W}=\mathrm{O}$ units (i.e. $(\mathrm{HO})_{2} \mathrm{Mo}(\mathrm{O})\left(\mathrm{CH}_{2}\right)$ and $(\mathrm{HO})_{2} \mathrm{~W}(\mathrm{O})\left(\mathrm{CH}_{2}\right)$ as simple models of the proposed active sites of the corresponding industrial catalysts. We obtain very similar results for both systems and will hence only discuss the Mo-based system, and provide comparative results for the W-based system in Table 1 . During the [2+2] cycloaddition reaction, the metal alkylidene transforms into a metallacyclobutane of trigonal bipyramidal (TBP) geometry. We also calculated the corresponding square pyramidal (SP) metallacyclobutane, which is an off-cycle intermediate in the olefin metathesis process and 
corresponds to the metallacyclobutane considered by Rappé and Goddard. Upon [2+2] cycloaddition of ethylene to the alkylidene, the $\mathrm{Mo}=\mathrm{O}$ distance increases from $1.661 \AA$ in the alkylidene to $1.680 \AA$ in the TBP metallacyclobutane. The $\mathrm{Mo}=\mathrm{O}$ distance in the SP metallacyclobutane is calculated at $1.660 \AA$ and is hence similar to that in the alkylidene. We subsequently calculated the ${ }^{17} \mathrm{O} N M R$ parameters of the oxo ligand in all three structures. The results of these calculations are shown in Fig. 4. As can be seen, the oxo ligand in the metal alkylidene shows two highly deshielded components. Hence, this oxo ligand already features an almost axially symmetric electronic structure which is indicative of a metal-oxo triple bond. Upon formation of the TBP metallacyclobutane the axial symmetry is slightly decreased; the overall broadening of the spectrum is mainly due to a larger quadrupolar coupling, which will not be discussed in detail. However, it should be noted that the $\mathrm{C}_{O}$ is particularly large for the TPB structure, which is associated with an increase of the Mo-O bond length, induced by the presence of an X-ligand trans to the oxo ligand. Notably, the axial symmetry is significantly more decreased in the SP metallacyclobutane, suggesting less metal-oxo triple bond character in this intermediate despite the shorter metal-oxygen bond distance.

The ${ }^{17} \mathrm{O}$ NMR parameters of the oxo ligand in the olefin metathesis reaction with a prototypical catalyst bearing a $\mathrm{Mo}=\mathrm{O}$ unit hence suggest that the spectator oxo ligand does not assist the metallacyclobutane formation by changing its bonding. Instead, it is best described as a triply bonded ligand throughout the whole catalytic cycle (comprising the alkylidene and the TBP metallacyclobutane), while some of the triple-bonding character is lost upon formation of the off-cycle SP metallacyclobutane intermediate.

Table 1 shows the results for the analogous analysis for the corresponding $\mathrm{W}$-oxo-alkylidene (i.e. $\left.(\mathrm{HO})_{2} \mathrm{~W}(\mathrm{O})\left(\mathrm{CH}_{2}\right)\right)$. Overall, the oxo ligand behaves in a similar way as in the Mo-homologue, indicating a large triple-bond character in the alkylidene and the TBP-intermediate, while some of this triple-bond character is lost in the off-cycle SP-intermediate.

Even if the role of the spectator oxo ligand in olefin metathesis might not be that inferred by Rappé and Goddard, the triple-bonding metal-oxo interaction along the catalytic cycle of olefin metathesis has important implications. Since the oxo ligand in the alkylidene intermediate is involved in two $\pi$-interactions with the metal, the angle between the oxo ligand and the alkylidene (which compete for the same d-orbital) is typically less than $109^{\circ}$ (what would be expected for four equivalent ligands), and sometimes even approaches $90^{\circ}{ }^{\circ}{ }^{[7]}$ The $[2+2]$ cycloaddition step is associated with the formation of the TBP metallacyclobutane, in which the angle between the metallacyclobutane-carbons and the axial oxo ligand is $90^{\circ}$. If the oxoMo-alkylidene angle is closer to $90^{\circ}$, the molecule undergoes a smaller structural rearrangement upon $[2+2]$-cycloaddition, hence lowering the barrier of this central step in olefin metathesis. Due to the inherent symmetry of olefin metathesis, a similar argument applies to the cycloreversion reaction, which is the microscopic reverse of the cycloaddition (Fig. 5). Upon conversion of the TBP metallacyclobutane to the off-cycle SP metallacyclobutane, the oxo ligand loses some of its triple-bonding character. This destabilizes the SP metallacyclobutane with respect to the TBP structure, hence modulating the relative stability of these two crucial intermediates of olefin metathesis. Hence, even though the oxo ligand in olefin metathesis might not play the role that was proposed by Rappé and Goddard, its presence crucially influences the electronic structure along the metathesis pathway, disfavouring the formation of unreactive intermediates.

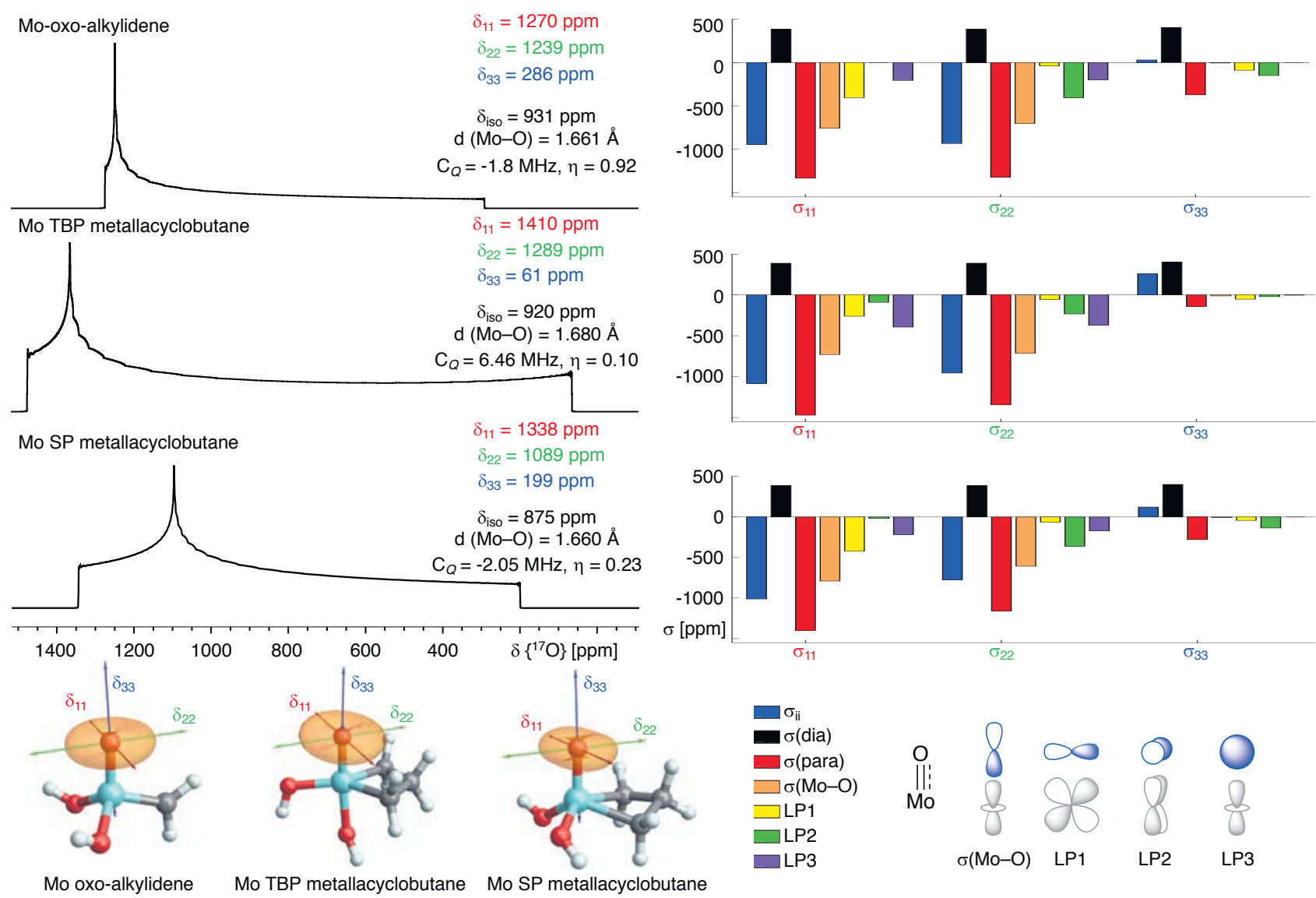

Fig. 4. Simulated NMR signature and orbital contributions to the shielding tensor of the molybdenum oxo-alkylidene species and the associated metallacyclobutanes (TBP and SP). 
Table 1. Chemical shift tensors, quadrupolar coupling parameters and metal-oxo distance in the prototypical Mo and W-oxo metathesis catalyst $(\mathrm{HO})_{2} \mathrm{M}(\mathrm{O})\left(\mathrm{CH}_{2}\right)$ and the corresponding metallacyclobutane structures.

\begin{tabular}{|l|l|l|l|l|l|l|l|}
\hline & $\boldsymbol{\delta}_{\text {iso }}$ [ppm] & $\boldsymbol{\delta}_{\mathbf{1 1}}[\mathbf{p p m}]$ & $\boldsymbol{\delta}_{\mathbf{2 2}}[\mathbf{p p m}]$ & $\boldsymbol{\delta}_{\mathbf{3 3}}[\mathbf{p p m}]$ & $\mathbf{C}_{\mathbf{Q}}[\mathbf{M H z}]$ & $\boldsymbol{\eta}$ & $\mathbf{d}(\mathbf{W}-\mathbf{O})[\AA \mathbf{A}]$ \\
\hline Mo-oxo-alkylidene & 931 & 1270 & 1239 & 286 & -1.8 & 0.92 & 1.661 \\
\hline Mo-oxo-TBP & 920 & 1410 & 1289 & 61 & 6.46 & 0.10 & 1.680 \\
\hline Mo-oxo-SP & 875 & 1339 & 1089 & 199 & -2.1 & 0.23 & 1.660 \\
\hline W-oxo-alkylidene & 809 & 1142 & 1101 & 183 & 2.02 & 0.76 & 1.689 \\
\hline W-oxo-TBP & 806 & 1221 & 1165 & 33 & 6.72 & 0.12 & 1.706 \\
\hline W-oxo-SP & 776 & 1199 & 1002 & 127 & -2.02 & 0.58 & 1.687 \\
\hline
\end{tabular}

Fig. 5. The role of the oxo ligand in olefin metathesis.

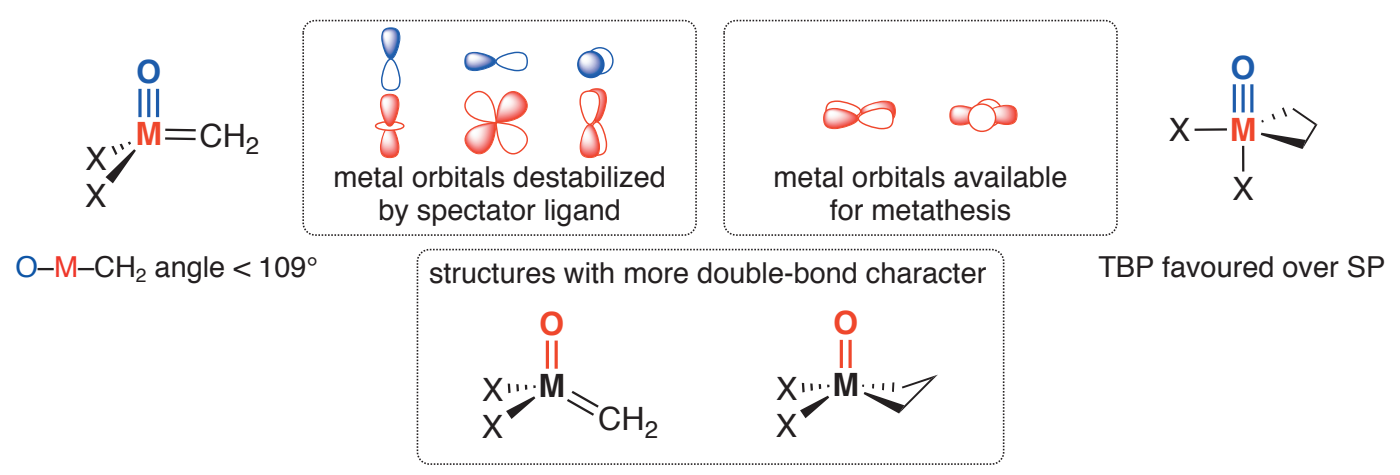

\section{Conclusion}

The analysis of ${ }^{17} \mathrm{O}$ NMR parameters obtained from DFT calculations allows for a detailed analysis of the electronic structure of oxo ligands. In particular, the ${ }^{17} \mathrm{O}$ NMR chemical shift tensor allows to easily distinguish metal-oxo double bonds from metal-oxo triple bonds, and is hence a convenient tool to probe the development of spectator oxo ligands throughout a chemical reaction. Our analysis on the olefin epoxidation with $\mathrm{H}_{2} \mathrm{O}_{2}$, catalysed by methyltrioxorhenium (MTO), shows that the spectator oxo ligand of MTO indeed changes its bonding from a Re-oxo double bond to a Re-oxo triple bond upon formation of the bisperoxo complex. In olefin metathesis on the other hand, the spectator oxo ligand does not seem to provide a driving force for the metallacyclobutane formation. Throughout the whole reaction the oxo ligand acts as a triply-bonded ligand. The oxo ligand does not stabilize the metallacyclobutane with respect to the alkylidene. Instead, it brings the alkylidene into a geometry that is closer to that of the transition state to $[2+2]$ cycloaddition and that of the metallacyclobutane. In addition, the triply-bonded spectator-oxo ligand modulates the relative energy of the trigonal-bipyramidal (TBP) metallacyclobutane, which is on the pathway of the catalytic cycle versus the square-pyramidal (SP) isomer, which is an off-cycle intermediate. Balancing the relative energy of these intermediates is central to catalysis, and the spectator ligand is one of the key design elements in the development of efficient catalysts. Overall, oxo ligands which are ubiquitous in transition metal catalysts can adopt various binding modes, thus modulating the electronic structure of the metal atom throughout the catalytic cycle.

\section{Acknowledgements}

Christopher P. Gordon is a recipient of the Scholarship Fund of the Swiss Chemical Industry (SSCI). We wish to thank Christian Ehinger and Erwin Lam for helpful discussions.

Received: February 14, 2020
[1] W. A. Nugent, J. M. Mayer, 'Metal-ligand multiple bonds: the chemistry of transition metal complexes containing oxo, nitrido, imido, alkylidene, or alkylidyne ligands', Wiley, New York, 1988.

[2] A. K. Rappé, W. A. Goddard, Nature 1980, 285, 311.

[3] A. K. Rappé, W. A. Goddard, J. Am. Chem. Soc. 1980, 102, 5114.

[4] A. K. Rappé, W. A. Goddard, J. Am. Chem. Soc. 1982, 104, 448.

[5] P. J.-L. Hérisson, Y. Chauvin, Die Makromol. Chem. 1971, 141, 161.

[6] X. Solans-Monfort, E. Clot, C. Copéret, O. Eisenstein, J. Am. Chem. Soc. 2005, 127, 14015 .

[7] A. Poater, X. Solans-Monfort, E. Clot, C. Copéret, O. Eisenstein, J. Am. Chem. Soc. 2007, 129, 8207.

[8] X. Solans-Monfort, C. Copéret, O. Eisenstein, Organometallics 2015, 34, 1668.

[9] C. P. Gordon, K. Yamamoto, W.-C. Liao, F. Allouche, R. A. Andersen, C. Copéret, C. Raynaud, O. Eisenstein, ACS Cent. Sci. 2017, 3, 759.

[10] J. Sundermeyer, Angew. Chem. Int. Ed. Engl. 1993, 32, 1144.

[11] D. V. Deubel, J. Sundermeyer, G. Frenking, J. Am. Chem. Soc. 2000, 122, 10101.

[12] W. A. Herrmann, R. W. Fischer, M. U. Rauch, W. Scherer, J. Mol. Catal. 1994, 86,243

[13] J. Rudolph, K. L. Reddy, J. P. Chiang, K. B. Sharpless, J. Am. Chem. Soc. 1997, 119, 6189.

[14] C. Copéret, H. Adolfsson, K. B. Sharpless, Chem. Commun. 1997, 1565.

[15] K. V. Bukhryakov, R. R. Schrock, A. H. Hoveyda, C. Tsay, P. Müller, J. Am. Chem. Soc. 2018, 140, 2797.

[16] F. Zhai, K. V. Bukhryakov, R. R. Schrock, A. H. Hoveyda, C. Tsay, P. Müller, J. Am. Chem. Soc. 2018, 140, 13609.

[17] C. M. Widdifield, R. W. Schurko, Concepts Magn. Reson., Part A 2009, 34A, 91.

[18] C. P. Gordon, C. Copéret, Chimia 2019, 73, 252.

[19] C. P. Gordon, C. Raynaud, R. A. Andersen, C. Copéret, O. Eisenstein, Acc. Chem. Res. 2019, 52, 2278.

[20] C. P. Gordon, R. A. Andersen, C. Copéret, Helv. Chim. Acta 2019, 102, e1900151.

[21] C. Ehinger, C. P. Gordon, C. Copéret, Chem. Sci. 2019, 10, 1786.

[22] M. J. Frisch, G. W. Trucks, H. B. Schlegel, G. E. Scuseria, M. A. Robb, J. R. Cheeseman, G. Scalmani, V. Barone, B. Mennucci, G. A. Petersson, H. Nakatsuji, M. Caricato, X. Li, H. P. Hratchian, A. F. Izmaylov, J. Bloino, G. Zheng, J. L. Sonnenberg, M. Hada, M. Ehara, K. Toyota, R. Fukuda, J. Hasegawa, M. Ishida, T. Nakajima, Y. Honda, O. Kitao, H. Nakai, T. Vreven, J. A. Montgomery, J. E. Peralta, F. Ogliaro, M. Bearpark, J. J. Heyd, E. Brothers, K. N. Kudin, V. N. Staroverov, R. Kobayashi, J. Normand, K. Raghavachari, A. Rendell, J. C. Burant, S. S. Iyengar, J. Tomasi, M. Cossi, N. Rega, J. M. Millam, M. Klene, J. E. Knox, J. B. Cross, V. Bakken, C. Adamo, J. Jaramillo, R. Gomperts, R. E. Stratmann, O. Yazyev, A. J. Austin, 
R. Cammi, C. Pomelli, J. W. Ochterski, R. L. Martin, K. Morokuma, V. G. Zakrzewski, G. A. Voth, P. Salvador, J. J. Dannenberg, S. Dapprich, A D. Daniels, Farkas, J. B. Foresman, J. V. Ortiz, J. Cioslowski, D. J. Fox, Gaussian09 (Gaussian Inc., Wallingford CT), 2009.

[23] C. Adamo, V. Barone, J. Chem. Phys. 1999, 110, 6158.

[24] F. Jensen, J. Chem. Theory Comput. 2014, 10, 1074.

[25] D. Andrae, U. Häußermann, M. Dolg, H. Stoll, H. Preuß, Theor. Chim. Acta 1990, 77,123

[26] M. Dolg, U. Wedig, H. Stoll, H. Preuss, J. Chem. Phys. 1987, 86, 866.

[27] G. te Velde, F. M. Bickelhaupt, E. J. Baerends, C. Fonseca Guerra, S. J. A van Gisbergen, J. G. Snijders, T. Ziegler, J. Comput. Chem. 2001, 22, 931.

[28] E. v. Lenthe, E. J. Baerends, J. G. Snijders, J. Chem. Phys. 1993, 99, 4597.

[29] E. van Lenthe, R. van Leeuwen, E. J. Baerends, J. G. Snijders, Int. J. Quantum Chem. 1996, 57, 281.

[30] NBO 6.0, E. D. Glendening, J. K. Badenhoop, A. E. Reed, J. E. Carpenter J. A. Bohmann, C. M. Morales, C. R. Landis, F. Weinhold, University of Wisconsin, Madison, 2013

[31] J. B. Lambert, R. Rittner, 'Recent advances in organic NMR spectroscopy', Norell Press, 1987

[32] N. F. Ramsey, Phys. Rev. 1950, 78, 699.

[33] J. A. Bohmann, F. Weinhold, T. C. Farrar, J. Chem. Phys. 1997, 107, 1173.

[34] J. Autschbach, J. Chem. Phys. 2008, 128, 164112.

[35] J. Autschbach, S. Zheng, R. W. Schurko, Concepts Magn. Reson., Part A 2010, 36A, 84
[36] M. Leskes, N. E. Drewett, L. J. Hardwick, P. G. Bruce, G. R. Goward, C. P. Grey, Angew. Chem. Int. Ed. 2012, 51, 8560.

[37] E. Lam, A. Comas-Vives, C. Copéret, J. Phys. Chem. C 2017, 121, 19946.

[38] E. Lam, C. Copéret, Helv. Chim. Acta 2018, 101, e1800120.

[39] D. B. Culver, W. Huynh, H. Tafazolian, T.-C. Ong, M. P. Conley, Angew. Chem. Int. Ed. 2018, 57, 9520.

[40] W.-D. Wang, J. H. Espenson, J. Am. Chem. Soc. 1998, 120, 11335.

[41] H. Adolfsson, C. Copéret, J. P. Chiang, A. K. Yudin, J. Org. Chem. 2000, 65, 8651.

[42] W. A. Herrmann, 'Synthetic Methods of Organometallic and Inorganic Chemistry', Vol. 10, Thieme, Stuttgart, 2002.

\section{License and Terms}

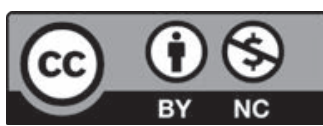

This is an Open Access article under the terms of the Creative Commons Attribution License CC BY_NC 4.0. The material may not be used for commercial purposes.

The license is subject to the CHIMIA terms and conditions: (http:// chimia.ch/component/sppagebuilder/?view=page \&id=12).

The definitive version of this article is the electronic one that can be found at doi:10.2533/chimia.2020.225 